\title{
KUALITAS DAN KENYAMANAN UDARA PADA GEDUNG PERKANTORAN BERTINGKAT RENDAH DENGAN STUDI KASUS GEDUNG PERKANTORAN PT. X DI JAKARTA
}

\author{
Putri Nur Ratnasari ${ }^{1}$, Dyah Nurwidyaningrum ${ }^{2}$ \\ ${ }_{1,2}$ Jurusan Teknik Sipil, Politeknik Negeri Jakarta, \\ Jalan Prof. Dr. G.A. Siwabessy, Kampus UI Depok, 16323, Indonesia \\ e-mail : pnuuratnasari@gmail.com ${ }^{l}$, nurwidyaningrum@yahoo.com ${ }^{2}$
}

\begin{abstract}
Green Building Council Indonesia (GBCI) publishes an assessment device called Greenship to be used as a benchmark in planning to maintain green buildings. PT. Medtek one of the low-rise office buildings in Jakarta that is an area with moderate air pollution level based on air Pollution Standard Index (ISPU) which has no effect on human or animal health but influential on sensitive plants and aesthetic values. This research aimed to know the criteria points obtained by PT. Medtek, influence of air quality, and building conditions in the user of the building. Measurements of indoor air health, comfort and questionnaire data collection is done indoors when user's activity in an office building is underway. The method used is a comparison method by comparing the results of field measurements with Greenship Rating Tools Existing Building version 1.1. The criteria achieved by PT. Medtek are a non-smoking campaign, outside air introduction, cigarette smoke control, and visual comfort. Criterion points earned 12 out of 18 scoring points are reviewed or meet $66.67 \%$ of the total assessment aspect of quality and comfort of indoor air.
\end{abstract}

Keywords: Green Building; Greenship; Air Pollution; Air Quality; Low-Rise Office

\begin{abstract}
ABSTRAK
Green Building Council Indonesia (GBCI) menerbitkan sebuah perangkat penilaian yang disebut Greenship untuk dijadikan sebuah tolak ukur dalam perencanaan hingga pemeliharaan untuk bangunan hijau. PT. $X$ salah satu gedung perkantoran bertingkat rendah di Jakarta dengan karateristik memiliki jumlah lantai 1 sampai dengan 3 dengan tinggi kurang dari $10 \mathrm{~m}$ yang berada pada daerah dengan tingkat polusi udara sedang berdasarkan Indeks Standar Pencemaran Udara (ISPU) yang kualitas udaranya tidak berpengaruh pada kesehatan manusia ataupun hewan namun berpengaruh pada tumbuhan yang sensitif dan nilai estetika. Penelitian ini bertujuan untuk mengetahui poin kriteria yang diperoleh PT. X, pengaruh kualitas udara, dan kondisi gedung pada pengguna gedung. Pengukuran Kualitas dan Kenyamanan Udara dalam Ruang dan pengumpulan data kuesioner dilakukan di dalam ruangan saat aktivitas pengguna di gedung perkantoran sedang berlangsung. Metode yang digunakan ialah metode komparasi yang membandingkan hasil pengukuran lapangan dengan Greenship Rating Tools Existing Building versi 1.1. Kriteria yang dicapai oleh PT. X ialah kampanye dilarang merokok, introduksi udara luar, pengendalian asap rokok, dan kenyamanan visual. Poin kriteria yang diperoleh 12 dari 18 poin penilaian yang ditinjau atau memenuhi 66,67\% dari total penilaian aspek kualitas dan kenyamanan udara dalam ruang.
\end{abstract}

Kata kunci: Green Building; Greenship; Polusi Udara; Kualitas Udara; Low-Rise Office

\section{PENDAHULUAN}

Di Jakarta, pertumbuhan sektor bangunan perkantoran meningkat dengan proyeksi penambahan supply pada periode 2015-2018 rata-rata meningkat menjadi $570.000 \mathrm{~m}^{2} /$ tahun dibandingkan pada periode 2010 [1][2]. Selain itu, aktivitas kendaraan bermotor dan gas buang industri mendominasi timbulnya konsentrasi polutan [3][4]. Beragam kegiatan ini membuat kualitas udara menjadi rendah yang erat 
korelasinya dengan kesehatan pengguna gedung yang dapat berdampak pada menurunnya produktivitas pengguna [5].

Penerapan konsep green building pada bangunan bertujuan untuk mengurangi dampak negatif bangunan terhadap lingkungan atau dari lingkungan terhadap bangunan tersebut dan dapat menghemat energi [6][7][8], salah satunya pada bangunan bertingkat rendah. Bangunan bertingkat rendah memiliki karakteristik jumlah lantai 1 sampai dengan 3 lantai dan tingginya kurang dari $10 \mathrm{~m}$ [9]. Green Building Council Indonesia (GBCI) yang didirikan tahun 2009 adalah suatu lembaga mandiri (non-government) dan nirlaba (nonprofit) yang berkomitmen terhadap pendidikan masyarakat dalam mengaplikasikan praktek-praktek terbaik lingkungan dan salah satu programnya adalah melakukan sertifikasi Bangunan Hijau di Indonesia berdasarkan perangkat penilaian khas Indonesia yang disebut Greenship [10]. Greenship sendiri dibagi menjadi 4 sesuai dengan peruntukan bangunan yang akan ditinjau, yakni Greenship untuk Bangunan Baru, Greenship untuk Bangunan Terbangun, Greenship untuk Ruang Dalam, Greenship untuk Rumah Tinggal, dan Greenship untuk Kawasan. Salah satu aspek dalam Greenship adalah Indoor Air Health and Comfort I IHC (Kualitas dan Kenyamanan Udara dalam Ruang).

Aspek Indoor Air Health and Comfort, salah satu aspek penting dalam konsep green building bukan sekedar kualitas udara dalam ruangan, namun juga mempunyai korelasi dengan kesehatan dan kenyamanan dari penghuni gedung [4][11][12]. Dalam buku Panduan Penerapan Greenship Rating Tools untuk Bangunan Terbangun versi 1.1 yang diterbitkan Green Building Council Indonesia, aspek IHC memiliki 1 kriteria pra-syarat dengan kode P1 dan
7 kriteria poin dengan kode IHC 1-IHC 8, yaitu Kampanye Dilarang Merokok, Introduksi Udara Luar, Pengendalian Asap Rokok, Pemantauan Kadar CO dan $\mathrm{CO}_{2}$, Polutan Fisik, Kimia, dan Biologi, Kenyamanan Suhu, Kenyamanan Visual, Tingkat Kebisingan, dan Survei Pengguna Gedung [13].

Kontribusi penelitian ini adalah untuk menghasilkan gambaran pengaruh kualitas udara di daerah Petojo Selatan pada Gedung Perkantoran PT. X yang menunjukkan ketercapaian poin dipengaruhi oleh kualitas udara di sekitar gedung perkantoran. Kemudian dapat menjadi masukan dalam pemeliharaan gedung perkantoran di lokasi yang tingkat kemacetan dan kepadatan tinggi agar memberikan kenyamanan pada pengguna gedung, menjadi acuan gedung perkantoran sejenis untuk memperoleh poin yang optimal pada aspek Kualitas dan Kenyamanan Udara dalam Ruang berdasarkan Greenship untuk Bangunan Terbangun versi 1.1, serta memberikan masukan kepada pihak pengelola gedung perkantoran PT. X untuk meningkatkan aspek Kualitas dan Kenyamanan Udara dalam Ruang berdasarkan Greenship untuk Bangunan Terbangun versi 1.1.

\section{METODE PENELITIAN}

PT. X adalah perusahaan swasta yang bergerak di bidang kesehatan dan alat kesehatan rumah sakit khususnya pengadaan, pemasangan, dan perawatan alat kesehatan di mana lokasinya berada di antara jalan raya dengan tingkat kemacetan tinggi serta kawasan perkantoran dengan tingkat kepadatan tinggi. Selain itu, Gedung Perkantoran PT. $X$ adalah gedung eksisting yang belum menerapkan konsep green building khususnya aspek Kualitas dan Kenyamanan Udara dalam Ruang. 
Penelitian ini mengambil lokasi pada 11 unit sampel dengan titik pengukuran di setiap lantai yang ada. Metode pengumpulan data penelitian yang digunakan, yaitu data primer dan data sekunder.

Data primer adalah data yang diperoleh langsung di lokasi penelitian dengan metode observasi dan pengukuran.

Observasi yang dilakukan untuk melihat apakah adanya kampanye dilarang merokok berupa stiker atau poster, tipe ventilasi pengudaraan, bangunan atau area khusus merokok di luar gedung.

Pengukuran yang dilakukan meliputi pengukuran konsentrasi Karbon Monoksida (CO), suhu, dan kelembapan menggunakan alat Air Quality Meter, Volatile Organic Compound (VOC) menggunakan alat Air Tester, kuat pencahayaan menggunakan alat $L u x$ Meter, dan tingkat kebisingan menggunakan alat Sound Level Meter.

Data sekunder dalam penelitian ini studi literatur menggunakan data yang berkaitan dari jurnal dan data arsip dari Gedung Perkantoran PT. X.

Observasi dan pengukuran dilakukan sejak bulan Maret hingga Juni 2019 dengan waktu pengukuran dilaksanakan mulai pukul 09.00-15.00 WIB dengan mempertimbangkan aktivitas optimal para pengguna gedung sehingga didapatkan hasil yang relevan terhadap tingkat kenyamanan pengguna gedung.

Variabel penelitian ini adalah pengaruh kualitas dan kenyamanan udara dalam ruang terhadap perolehan poin berdasarkan Greenship untuk Bangunan Terbangun versi 1.1. Metode yang digunakan adalah metode komparasi dengan membandingkan standar yang berkaitan kondisi di lokasi penelitian dengan aspek Kualitas dan Kenyamanan Udara dalam Ruang berdasarkan Greenship Rating Tools Existing Building version 1.1

\section{HASIL dan PEMBAHASAN}

Penilaian aspek Kualitas dan Kenyamanan Udara dalam Ruang berdasarkan Greenship Existing Building version 1.1 dapat dilihat pada Tabel 1. Hasil observasi awal menunjukkan kriteria Kampanye Dilarang Merokok telah memenuhi poin prasyarat. Hal ini ditandai dengan pihak pengelola sudah membuat surat pernyataan larangan merokok dan telah memasang stiker dan poster terkait kampanye dilarang merokok di beberapa titik gedung perkantoran. Meskipun sudah terpenuhi, penulis masih melihat aktivitas merokok di sekitar gedung perkantoran.

Untuk kriteria Introduksi Udara Luar mendapatkan 2 poin. Hasil pengukuran menunjukkan seluruh unit sampel sesuai baku mutu $\left(V_{b z}=56,496 \mathrm{~L} / \mathrm{s}\right.$ person $>$ $8,5 \mathrm{~L} / \mathrm{s}$ person) [14]. Hal ini ditunjukkan dari kebutuhan jumlah udara segar dalam ruangan terpenuhi serta penulis melihat bahwa udara segar dapat terpenuhi karena tipe bukaan yang digunakan berupa kisi-kisi, sehingga pertukaran udara dapat terjadi secara dinamis [15][16].

Selanjutnya, untuk kriteria Pengendalian Asap Rokok mendapatkan 2 poin. Hal ini karena dari hasil observasi telah diberlakukan aturan dilarang merokok dan area khusus merokok di luar gedung belum tersedia hingga sekarang. Meskipun upaya untuk meminimalisir aktivitas merokok tersebut telah diterapkan, penulis masih melihat beberapa pelanggaran.

Lalu pada kriteria Polutan Fisik, Kimia, dan Biologi memperoleh 7 poin. Data hasil pengukuran kualitas udara parameter karbon monoksida (CO) dan parameter Volatile Organic Compound (VOC) seluruh unit sampel memenuhi 
baku mutu $(\mathrm{CO}=1,164 \mathrm{ppm}<8 \mathrm{ppm}$ [13]; VOC $=0,001 \mathrm{mg} / \mathrm{m}^{3}<0,37$ $\mathrm{mg} / \mathrm{m}^{3}$ [17]). Selanjutnya dilakukan observasi pada setiap unit sampel dan hasilnya tidak ada debu yang menempel pada perabotan dan barang di ruangan. Pada plafon digunakan penutup berupa gypsum board yang tidak mengandung asbestos dan kadar Volatile Organic Compound (VOC) rendah. Untuk pembersihan filter, coil pendingin, dan alat bantu Ventilation and Air Conditioning (VAC) telah dilakukan perawatan secara berkala sehingga mencegah mikroorganisme untuk berkembangbiak. Seluruh tolak ukur dapat terpenuhi karena adanya komitmen dari pengelola untuk menjaga dan memelihara kebersihan gedung perkantoran [18].

Untuk kriteria Kenyamanan Suhu tidak memperoleh poin. Hasil pengukuran menunjukkan seluruh unit sampel melebihi baku mutu (Suhu $=32,3^{\circ} \mathrm{C}>$ $24^{\circ} \mathrm{C}-27^{\circ} \mathrm{C}$; kelembapan $=76,5 \%>$ $60 \% \pm 5 \%$ ) [13]. Meskipun dari data pengukuran seluruh unit melebihi baku mutu namun penulis mengamati bahwa para pengguna sudah dapat beradaptasi dengan kondisi suhu dan kelembapan yang cukup tinggi sehingga tidak terpengaruh pada produktivitas pengguna. Salah satu cara yang dilakukan oleh pengguna untuk menyesuaikan diri adalah dengan penggunaan AC meskipun penggunaan AC dengan suhu rendah membuatnya bekerja lebih keras dan lebih boros energi [19].

Untuk kriteria Kenyamanan Visual memperoleh 1 poin. Hasil pengukuran menunjukkan seluruh unit sampel sesuai baku mutu (Lobi $=310,727$ lux $>100$ lux ; Ruang Kerja $=378$, 25 lux $>350$ lux) [20]. Hal ini ditunjukkan dengan kombinasi pencahayaan alami dan buatan yang baik sehingga membuat pengguna gedung merasa tidak merasakan kelelahan mata karena merasa ruangan yang digunakan tidak terlalu silau atau terlalu gelap. Namun, penulis mengamati masih terdapat beberapa ruangan dengan nilai pencahayaan yang terlalu tinggi dapat berakibat pada penggunaan energi yang berlebihan.

Untuk kriteria Tingkat Kebisingan tidak memperoleh poin. Hasil pengukuran menunjukkan seluruh unit sampel melebihi baku mutu $(66,254 \mathrm{dBA}>40$ - 45 dBA) [21]. Meskipun dari data pengukuran seluruh unit melebihi baku mutu namun penulis mengamati bahwa para pengguna sudah dapat beradaptasi dengan kondisi suhu dan kelembapan yang cukup tinggi sehingga tidak terpengaruh pada produktivitas pengguna.

Untuk kriteria Survei Pengguna Gedung tidak memperoleh poin. Pihak pengelola belum melakukan survei kepada para pengguna gedung hingga saat ini meskipun secara berkala pihak pengelola selalu melakukan perawatan demi menjaga kebersihan dan kenyamanan gedung perkantoran.

Berdasarkan hasil kuesioner responden pada Bagan 1. menunjukkan kebersihan dan kondisi udara pada gedung perkantoran berpendapat sudah baik. Namun beberapa pengguna $(8,06 \%+$ $1,94 \%=10 \%)$ masih merasakan pengaruh kondisi gedung pada pengguna kurang baik. Hal ini berpengaruh pada ketidaknyamanan pengguna gedung yang disebabkan tingkat kebisingan yang cukup tinggi karena lokasi gedung berbatasan dengan jalan raya.

Dalam segi kondisi material bangunan dalam ruang yang digunakan, PT. X menggunakan material dinding dan finishing yang ramah lingkungan, antara lain bahan dinding dipilih menggunakan batu bata merah dengan karakteristik 
tahan api, kuat terhadap tekanan tinggi, daya serap air rendah, kedap suara, dan menyerap panas matahari secara signifikan, plafon menggunakan gypsum bebas asbestos dengan karakteristik lebih tahan api, finishing-nya lebih rapi dan lebih halus dibandingkan dengan penggunaan tripleks untuk plafon, dan cat dinding yang digunakan memiliki kadar Volatile Organic Compound (VOC) mendekati nol.

\section{KESIMPULAN}

Dari pembahasan yang dilakukan mengenai aspek Kualitas dan Kenyamanan Udara dalam Ruang berdasarkan Greenship untuk Bangunan Terbangun versi 1.1 pada Gedung Perkantoran PT. X menunjukkan poin yang diperoleh sebesar 12 poin dari total poin maksimal sebesar 18 poin atau sebesar $66,67 \%$. Ketercapaian poin ini dipengaruhi oleh finishing bangunan dalam ruang yang baik karena ditunjang dari aktivitas pengguna yang memenuhi aktivitas tidak merokok di dalam ruang sehingga memenuhi kualitas udara parameter karbon monoksida (CO). Kemudian, kondisi kombinasi pencahayaan alami dan buatan mempengaruhi kecukupan nilai tingkat pencahayaan dalam ruang gedung perkantoran. Sedangkan kebisingan dari luar gedung perkantoran belum dapat diantisipasi dengan baik oleh material ataupun kondisi lingkungan perkantoran serta gedung perkantoran tersebut belum dapat mengantisipasi kondisi suhu ruang dan kelembapan yang terlalu tinggi.

Dalam penelitian ini kriteria Pemantauan Kadar $\mathrm{CO}$ dan $\mathrm{CO}_{2}$ di penelitian ini tidak dilakukan perhitungan terkait parameter kadar $\mathrm{CO}$ dan $\mathrm{CO}_{2}$ karena kurang efektif. Hal ini disebabkan pada gedung perkantoran tidak tersedia parkir di area basemen. Penulis menyarankan untuk melakukan penelitian lanjutan yang mengeksplorasi pengaruh umur dan material bangunan pada kualitas dan kenyamanan udara.

\section{UCAPAN TERIMAKASIH}

Penulis mengucapkan terima kasih kepada Pusat Penelitian Pengabdian Masyarakat (P3M) Politeknik Negeri Jakarta atas hibah Bantuan Tugas Akhir Mahasiswa (BTAM) tahun 2019.

\section{DAFTAR PUSTAKA}

[1] M. R. A. Simanjuntak dan R. B. H. Manik, "KAJIAN AWAL SISTEM MANAJEMEN PENGENDALIAN MUTU DALAM MENINGKATKAN KINERJA WAKTU PROSES KONSTRUKSI BANGUNAN GEDUNG TINGGI HUNIAN DI DKI JAKARTA," hal. 258-264, 2019.

[2] M. Fauzan dan A. Dyah, "Perancangan Rental Office Di Jakarta Dengan Penerapan Arsitektur Futuristik," Maestro, vol. 2, no. 1, hal. 109-115, 2019.

[3] S. Pratiwi, "PENGGUNAAN DATA SATELIT GIOVANNI DALAM PEMANTAUAN KUALITAS UDARA," hal. 1-5, 2019.

[4] S. Hastutiningrum, S. Sunarsih, dan Imelda, "Analisis Hubungan Aktivitas Kendaraan Bermotor Terhadap Konsentrasi So2 Dan No2 Di Udara Ambien (Studi Kasus: Jl. Panembahan Senopati Yogyakarta)," J. Teknol. Technoscientia, vol. 11, no. 1, hal. 85-94, 2018.

[5] "Kualitas Udara Dalam Ruang Perpustakaan Universitas "X" Ditinjau Dari Kualitas Biologi, Fisik, Dan Kimiawi *)," Makara Seri Kesehat., vol. 12, no. 2, hal. 76-82, 2008.

[6] S. Handayani dan F. Suryani, 
"PENERAPAN

VALUE

ENGINEERING

PADA

\section{PROYEK}

GEDUNG

BANGUNAN

BERDESAIN

GREEN BUILDING DENGAN

MEMBANDINGKAN

PENGGUNAAN," vol. 2, no. 1, hal. 7-10, 2018.

[7] Anisah, I. Inayati, F. X. N. Soelami, dan R. Triyogo, "Identification of Existing Office Buildings Potential to Become Green Buildings in Energy Efficiency Aspect," Procedia Eng., vol. 170, hal. 320-324, 2017.

[8] M. S. A. Barra Pasuka Dewa, Agung Murti Nugroho, "Kajian Green Building Pada Gedung Dekanat Fakultas Teknik Universitas Brawijaya Malang," 2012.

[9] Mulyono, "Petunjuk Standarisasi Desain Gedung Bertingkat," Gancea Exact, 2000.

[10] E. Prianto dan B. Sujono, "SEMARANG," vol. II, no. 1, hal. 81-98, 2017.

[11] J. G. Allen, P. MacNaughton, J. G. C. Laurent, S. S. Flanigan, E. S. Eitland, dan J. D. Spengler, "Green Buildings and Health," Curr. Environ. Heal. reports, vol. 2, no. 3, hal. 250-258, 2015.

[12] A. Steinemann, P. Wargocki, dan B. Rismanchi, "Ten questions concerning green buildings and indoor air quality," Build. Environ., vol. 112, no. 2017, hal. 351-358, 2017.

[13] Green Building Council Indonesia, "Greenship Existing Building Version 1.1," 2016.

[14] R. L. Hedrick et al., "Ventilation for Acceptable Indoor Air Quality ASHRAE Staff Liaison: Mark Weber," vol. 2013, 2013.

[15] P. A. T.A. Fikriyah, "Konsep Green Building Pada Bangunan Kantor Spazio, Surabaya," Fak.
Tek. Univ. Brawijaya, hal. 1-8, 2016.

[16] A. Sarinda, Sudarti, dan Subiki, "Analisis Perubahan Suhu Ruangan Terhadap Kenyamanan Termal di Gedung 3 Fkip Universitas Jember," $J$. Pembelajaran Fis., vol. 6, no. 3, hal. 305-311, 2017.

[17] Anonim, Nilai Ambang Batas ( $N A B$ ) Zat Kimia di Udara Tempat Kerja. 2005.

[18] C. I. Prasasti, J. Mukono, dan Sudarmaji, "Pengaruh Kualitas Udara Dalam Ruangan Ber -AC Terhadap Gangguan Kesehatan," Kesehat. Lingkung., vol. 1, no. 2, hal. 160-170, 2005.

[19] A. K. Surakarta et al., "Penerapan Prinsip Arsitektur Hijau pada Bangunan Kantor Sewa di Surakarta," vol. 2, no. 2, hal. 415-424, 2019.

[20] Anonim, Konservasi Energi pada Sistem Pencahayaan. 2000.

[21] Anonim, Spesifikasi Tingkat Bunyi dan Waktu Dengung dalam Bangunan Gedung dan Perumahan. 2000. 
Putri Nur Ratnasari, Dyah Nurwidyaningrum, Kualitas dan Kenyamanan.....

Tabel 1. Hasil Penilaian Aspek Kualitas dan Kenyamanan Udara dalam Ruang

\begin{tabular}{|c|c|c|c|c|c|}
\hline Kriteria & Kode & Parameter & Hasil & Po & \\
\hline & & & & Tercapai & Standar \\
\hline $\begin{array}{l}\text { Kampanye } \\
\text { Dilarang } \\
\text { Merokok }\end{array}$ & P 1 & $\begin{array}{lrr}\text { Surat pernyataan } & \text { komitmen } \\
\text { minimalisasi aktivitas merokok } \\
\text { dalam gedung dan kampanye } \\
\text { dilarang merokok berupa } \\
\text { pemasangan stiker atau poster }\end{array}$ & $\begin{array}{l}\text { Surat pernyataan } \\
\text { minimalisasi aktivitas merokok } \\
\text { dalam gedung sudah dibuat dan } \\
\text { kampanye dilarang merokok } \\
\text { berupa pemasangan stiker atau } \\
\text { poster telah dilakukan }\end{array}$ & $\mathrm{P}$ & $\mathrm{P}$ \\
\hline $\begin{array}{l}\text { Introduksi } \\
\text { Udara Luar }\end{array}$ & IHC 1 & 8,5 L/s person & $54,497 \mathrm{~L} / \mathrm{s}$ person & 2 & 2 \\
\hline $\begin{array}{l}\text { Pengendalian } \\
\text { Asap Rokok }\end{array}$ & IHC 2 & $\begin{array}{l}\text { Apabila menyediakan area khusus } \\
\text { merokok di luar gedung harus } \\
\text { berjarak minimal } 5 \mathrm{~m} \text { dari pintu } \\
\text { masuk, tempat masuknya udara } \\
\text { segar, dan bukaan jendela dengan } \\
\text { tindak lanjut prosedur } \\
\text { pemantauan, dokumentasi, dan } \\
\text { sistem tanggap terhadap larangan } \\
\text { merokok }\end{array}$ & $\begin{array}{l}\text { Tidak ditermukan area khusus } \\
\text { merokok baik di luar maupun di } \\
\text { dalam gedung hingga saat ini }\end{array}$ & 2 & 2 \\
\hline $\begin{array}{l}\text { Polutan Fisik, } \\
\text { Kimia, dan } \\
\text { Biologi }\end{array}$ & IHC 4 & $\begin{aligned} \mathrm{CO} & =8 \mathrm{ppm} \\
\mathrm{VOC} & =0,37 \mathrm{mg} / \mathrm{m}^{3}\end{aligned}$ & $\begin{array}{ll}\mathrm{CO} & =8 \mathrm{ppm} \\
\mathrm{VOC} & =0,37 \mathrm{mg} / \mathrm{m}^{3}\end{array}$ & 7 & 7 \\
\hline $\begin{array}{l}\text { Kenyamanan } \\
\text { Suhu }\end{array}$ & IHC 5 & $\begin{array}{ll}\text { Suhu } & =24^{\circ} \mathrm{C}-27^{\circ} \mathrm{C} \\
\text { Kelembapan } & =60 \% \pm 5 \%\end{array}$ & $\begin{array}{ll}\text { Suhu } & =24^{\circ} \mathrm{C}-27^{\circ} \mathrm{C} \\
\text { Kelembapan } & =60 \% \pm 5 \%\end{array}$ & 0 & 1 \\
\hline $\begin{array}{l}\text { Kenyamanan } \\
\text { Visual }\end{array}$ & IHC 6 & $\begin{array}{ll}\text { Lobi } & =100 \operatorname{lux} \\
\text { R. Kerja } & =350 \operatorname{lux}\end{array}$ & $\begin{array}{ll}\text { Lobi } & =100 \operatorname{lux} \\
\text { R. Kerja } & =350 \operatorname{lux}\end{array}$ & 1 & 1 \\
\hline $\begin{array}{l}\text { Tingkat } \\
\text { Kebisingan }\end{array}$ & IHC 7 & $40-45 \mathrm{dBA}$ & $66,254 \mathrm{dBA}$ & 0 & 1 \\
\hline $\begin{array}{l}\text { Survei } \\
\text { Pengguna } \\
\text { Gedung }\end{array}$ & IHC 8 & $\begin{array}{l}\text { Pihak pengelola melakukan survei } \\
\text { pengguna gedung }\end{array}$ & $\begin{array}{l}\text { Pihak pengelola belum melakukan } \\
\text { survei pengguna gedung hingga } \\
\text { saat ini }\end{array}$ & 0 & 3 \\
\hline
\end{tabular}

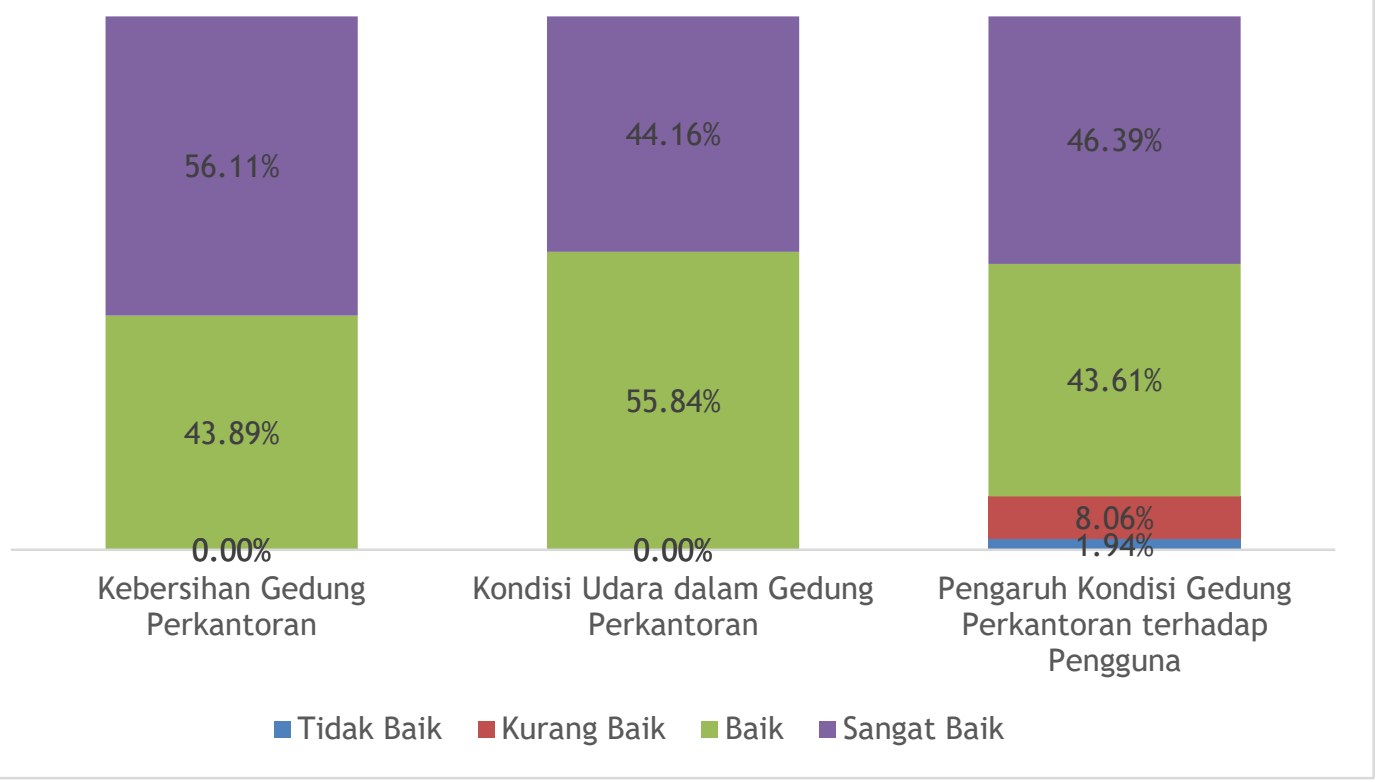

Bagan 1. Persepsi Responden pada Gedung Perkantoran 